Meteorol. Atmos. Phys. 43, 231-234 (1990)

Meteorology and Atmospheric Physics

(C) by Springer-Verlag 1990

$551.501(23)$

DLR, Institut für Physik der Atmosphäre, Oberpfaffenhofen, Federal Republic of Germany

\title{
An Alpine Orography Resolving Major Valleys and Massifs
}

\author{
H. Volkert \\ With 3 Figures \\ Received August 6, 1989
}

\begin{abstract}
Summary
A model orographiy is constructed for a large portion of the Alpine region with nearly equidistant zonal and meridional resolution $(3.3 \mathrm{~km})$. Major valleys and massifs, which tend to be smeared out by averaging a high resolution database, are manually reconstructed. A comparison along a crosssection over the crest line of the Eastern Alps in both physical and Fourier space reveals the characteristics of different model resolutions.
\end{abstract}

\section{Introduction}

The representation of orography in numerical weather prediction models constitutes a severe difficulty. In recent years suggestions have been made of how to incorporate a massif as the Alps (1000 km long, less than $400 \mathrm{~km}$ wide) in models which mainly resolve synoptic scale features (e.g. Bleck, 1977; Wallace et al., 1983; typical meshsize: 50 to $100 \mathrm{~km}$ ). The basic idea is to enhance the mean orographic height of a grid cell by adding a multiple of the subgrid scale distribution's standard deviation. Such an "envelope" orography produces more realistic crest heights, but fills in valleys. This has been justified by stating that mountain valleys are often filled with stagnant air which prevents the valley bottom, whatever its elevation may be, from exerting any dynamical influence on the cross-barrier flow.

The situation changes when the model resolu- tion is decrased and truely meso-scale phenomena are to be resolved. With the computational resources and numerical techniques available (e.g. the meso-scale model Mesoscop; see Schumann et al., 1987) it becomes feasible to calculate the airflow over and around the entire Alps using a meshsize of $5 \mathrm{~km}$ or less. Now major valleys and massifs can be explicitly resolved and the question arises of how to obtain an orography which is representative for this scale.

Different databases are available which are not restricted to single Alpine countries. Orographic heights for entire Europe are distributed by the U.S. Geophysical Survey (resolution: $5^{\prime}=300^{\prime \prime}$ ). For a large part of the Alpine region $\left(6^{\circ} \leqslant \lambda \leqslant 16^{\circ}\right.$; $46^{\circ} \leqslant \varphi \leqslant 48^{\circ}$ ) a $3^{\prime \prime}$ resolution database could be obtained from the German military geographical service. A cross-section through both datasets along $\varphi=47^{\circ} 06.5^{\prime}$ from the Swiss midlands across the crest of the Eastern Alps to the southern part of Burgenland (Austria) is displayed in Fig. 1 (bottom and top line; displaced by $\pm 2 \mathrm{~km}$, respectively).

\section{Construction of a Meso-Scale Model Orography}

For the construction of a model orography with the features "resolution better than 5", "more equidistant spacing in meridional and zonal direction", and "hydrographically correct major 


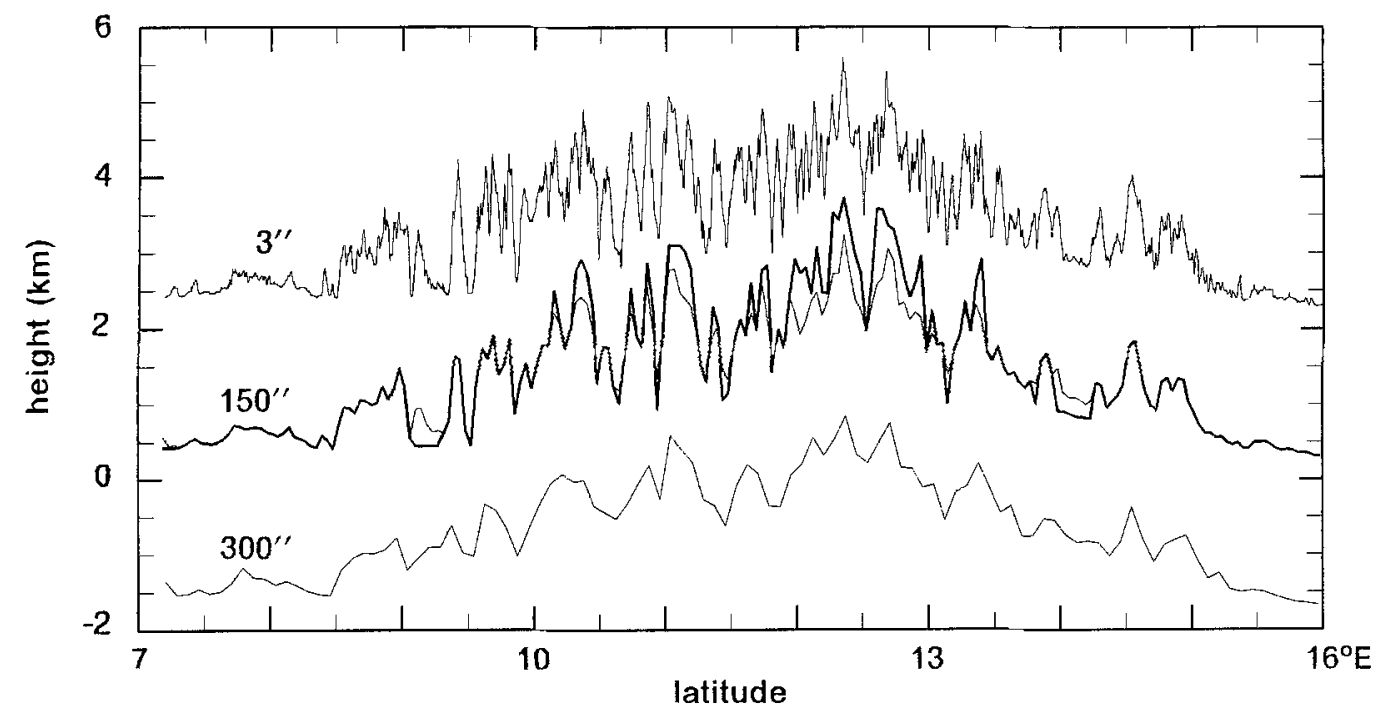

Fig, 1. Cross-section of four types of orographies along $\varphi=47^{\circ} 06.5^{\prime}$ (cf. Fig. 2) along the crest of the Eastern Alps. Top: $3^{\prime \prime}$ resolution (displaced by $+2000 \mathrm{~m}$ ); middle: $150^{\prime \prime}$ zonal resolution (first guess data: light; corrected data: bold); bottom: $300^{\prime \prime}$ resolution (displaced by $-2000 \mathrm{~m}$ )

valleys" we propose the following procedure: (a) specify a suitable meshsize, i.e. wide enough to cover the entire Alps with less than 300 gridpoints in every direction and fine enough to resolve major valleys, (b) obtain first guess elevations for the resulting pixels by averaging the high resolution database; (c) decide which valleys are to appear consistently in the resulting approximated orography and correct valley floor elevations by fitting the valley to the rectangular grid and by linear interpolating heights between a few selected points along the valley; (d) check which major massifs were underestimated by the averaging procedure and enhance their elevations.

An example which was obtained by this procedure is given in Fig. 2 for the northern part of the Alpine arc. $38 \times 50$ heights from the $3^{\prime \prime}$ database were averaged to obtain the first guess elevations with a resolution of $\Delta \lambda=1 / 24^{\circ}, \Delta \varphi=$ $1 / 32^{\circ}$ (equivalent to $\Delta x \sim \Delta y \sim 3.3 \mathrm{~km}$ ). The valleys and massifs given in Table 1 were corrected using a system of topographic maps (scale $1: 250000$ ), which cover the entire Alps. A comparison with the superimposed rivers and lakes (digitized from an atlas) gives an impression which orographic details could be resolved and which are still of sub-grid scale. The light profile in the middle of Fig. 1 shows the first guess values along the cross-section, whereas the bold line stands for the corrected heights with enhanced valleys and massifs. Statistical details along the cross-section are given in Table 2 for all four orography types.

Table 1. List of Manually Corrected Valleys and Massifs

\begin{tabular}{lll}
\hline Valleys & & Massifs \\
\cline { 3 - 3 } Rhine & Gail & Berner Alpen \\
Lech & Save & Glarner Alpen \\
Isar & Tagliamento & Walliser Alpen \\
Inn & Piave & Tessiner Alpen \\
Ötz/Ziller & Adige & Rätische Alpen \\
Salzach & Isarco & Lechtaler Alpen \\
Enns & Adda & Wetterstein \\
Mur & Lago di Como & Ötztaler Alpen \\
Mürz & Ticino/Lago Maggiore & Stubaier Alpen \\
Drau & Toce & Salzburger Alpen \\
Lavant & Rhône/Arve & Hohe Tauern \\
Gurk & Aare & Niedere Tauern \\
\hline
\end{tabular}

Table 2. Characteristics of Different Orographies Along the Cross-Section Displayed in Fig. 1

\begin{tabular}{lrrrr}
\hline Zonal resolution & $300^{\prime \prime}$ & $\begin{array}{c}150^{\prime \prime} \\
\text { corrected }\end{array}$ & $\begin{array}{c}150^{\prime \prime} \\
\text { first guess }\end{array}$ & $3^{\prime \prime}$ \\
\hline Number of points & 108 & 216 & 216 & 10800 \\
Mean (m) & 1357 & 1440 & 1369 & 1381 \\
Standard deviation (m) & 655 & 883 & 711 & 750 \\
Minimum (m) & 327 & 310 & 310 & 294 \\
Maximum (m) & 2845 & 3726 & 3226 & 3600 \\
\hline
\end{tabular}




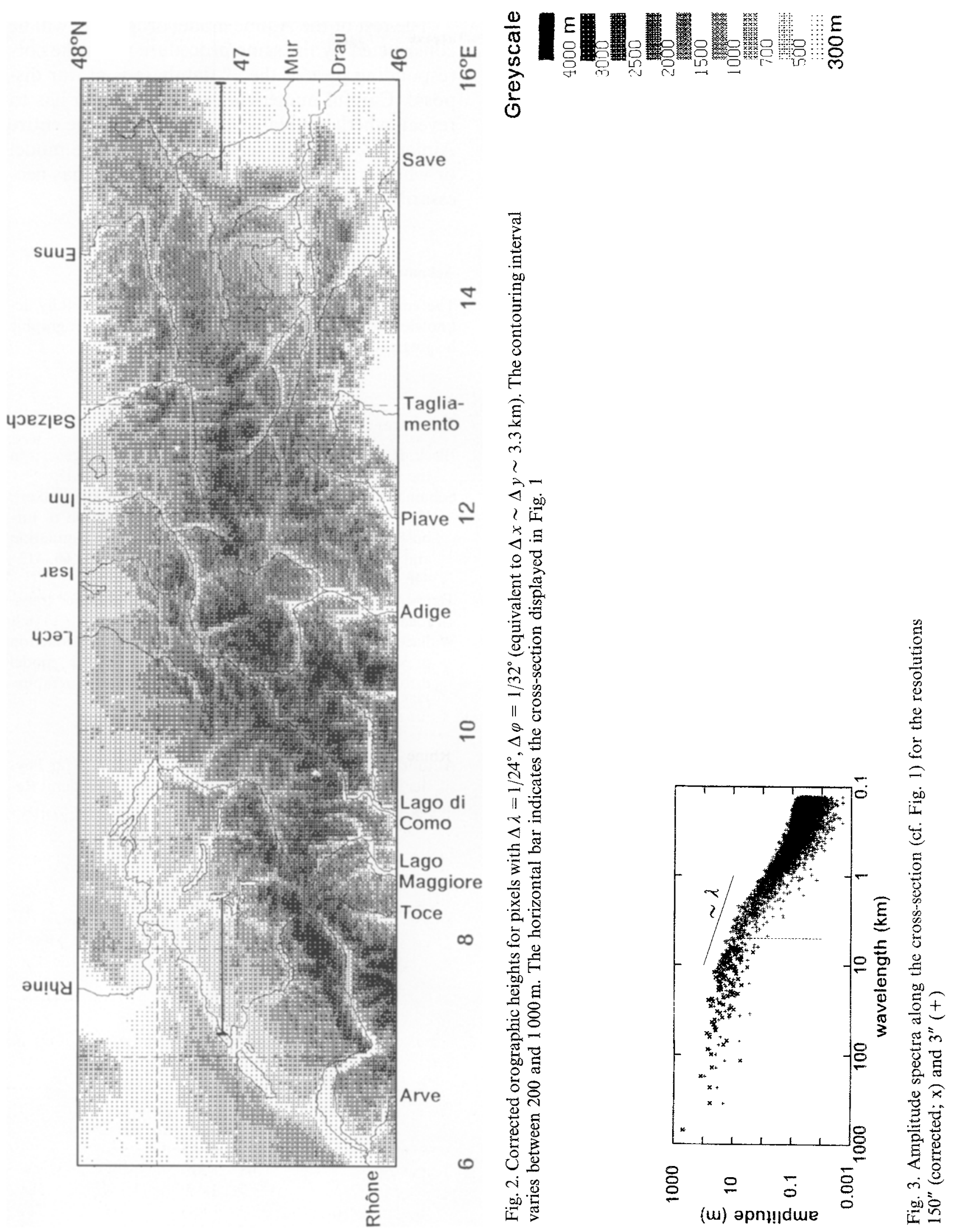




\section{Fourier Analysis and Discussion}

The amplitude spectra of the different orographies along the cross-section (cf. Fig. 1) were obtained by a fast Fourier transformation (following Temperton, 1983). In Fig. 3 the wavelength dependent characteristics of two different resolutions are shown. The bold crosses for wavelengths $\lambda>6.5 \mathrm{~km}$, i.e. to the left of the dashed line, mark the contributions of the corrected orography with 150 " zonal resolution, while the "cloud of plus signs" represents the contributions of the 3 " orography down to wavelengths of $130 \mathrm{~m}$. For the meso-scale range left of the dashed line both spectra appear to be similar, although they are not equal. The decay of amplitudes with decreasing $\lambda$ is steeper than the first power of $\lambda$, but there is no obvious limiting value below which smaller scale contribution could thought to be negligible.

In summary, we note that the orography is the best known component of the complicated problem of simulating the airflow over, around, and within the Alps. So, in our view, it is justified to put some effort in constructing a suitable model orography before starting the numerical experimentation. It has to be kept in mind that different presumptions are possible, e.g. to construct valleys that are hydrographically correct even if they must be artifically widened in places (method adopted here) or to specify dams where even major valleys are narrower than the grid size (e.g. Isarco north of Bozen or Salzach near Bischofshofen) and, thus, force the simulated airflow over them.
The rest of the Alpine model orography will be constructed by the same procedure when the corresponding part of the $3^{\prime \prime}$ database is at our disposal. Careful numerical experimentation has to reveal, whether a realistic simulation of the entire Alpine circulation is feasible with a single model or whether a hierarchy of nested models has necessarily be used.

\section{Acknowledgements}

The competent assistance of Jana Freund is gratefully acknowledged who applied the corrections to the orographic heights and programmed the plots of the figures.

\section{References}

Bleck, R., 1977: Numerical simulation of lee cyclogenesis in the gulf of Genoa. Mon. Wea. Rev., 105, 428-445.

Schumann, U., Hauf, T., Höller, H., Schmidt, H., Volkert, H., 1987: A mesoscale model for the simulation of turbulence, clouds and flow over mountains: Formulation and validation examples. Beitr. Phys. Atmosph., 60, 413446.

Temperton, C., 1983: Fast mixed-radix real Fourier transforms. J. Comput. Phys., 52, 340-350.

Wallace, J. M., Tibaldi, S., Simmons, A. J., 1983: Reduction of systematic forecast errors in the ECMWF model through the introduction of an envelope orography. Quart. J. R. Meteor. Soc., 109, 683-717.

Author's address: Dr. Hans Volkert, DLR, Institut für Physik der Atmosphäre, D-8031 Oberpfaffenhofen, Federal Republic of Germany. 